\title{
TECHNOLOGY TRANSFER FROM THE SPACE EXPLORATION INITIATIVE
}

\author{
David Buden \\ Idaho National Engineering Laboratory \\ P.O. Box 1625 \\ Idaho Falis, ID 83415-1550 \\ (208) 525-5626
}

EGG-M- -91482

DE92 003317

\section{DISCLAIMER}

\begin{abstract}
This report was prepared as an account of work sponsored by an agency of the United States Government. Neither the United States Government nor any agency thereof, nor any of their employees, makes any warranty, express or implied, or assumes any legal liability or responsibility for the accuracy, completeness, or usefulness of any information, apparatus, product, or process disclosed, or represents that its use would not infringe privately owned rights. Reference herein to any specific commercial product, process, or service by trade name, trademark, manufacturer, or otherwise does not necessarily constitute or imply its endorsement, recommendation, or favoring by the United States Governmeit or any agency thereof. The views and opinions of authors expressed herein do not necessarily state or reflect those of the United States Government or any agency thereof.
\end{abstract}

CAMERA READY MANUSCRIPT prepared for:

Ninth Symposium

on Space Nuclear Power Systems

Albuquerque, New Mexico

12-16 January 1992

initial submission: 14 June 1991

final submission:

Author to whom correspondence should be sent: Mr. David Buden 


\title{
TECHNOLOGY TRANSFER FROM THE SPACE EXPLORATION INITIATIVE
}

\author{
David Buden \\ Idaho National Engineering Laboratory \\ P.O. Box 1625 \\ Idaho Falls, ID 83415-1550 \\ (208) 525-5626
}

\begin{abstract}
space exploration has demonstrated that it stimulates the national economy by creating hew and improved products, increased employment, and provides a stimulus to education. The exploration of the Moon and Mars under the space Exploration Initiative has the potential of accelerating this stimulates to the economy. It is difficult to identify all if the concrete ways this will be accomplished. However, many areas can be identified. The space exploration building blocks of power, propulsion, spacecraft, robotics, rovers, mining and manufacturing, communications, navigation, habitats, life support and infrastructures are reviewed to identify possible technology areas. For example, better means for working in hazardous areas and handling hazardous waste are potential outcomes of this initiative. Methods to produce higher quality goods and improve America's competitiveness in manufacturing will undoubtedly evolve from the need to produce products that must last many years in the harsh environments of space and planetary surfaces. Some ideas for technology transfer are covered in this paper.
\end{abstract}

\section{INTRODUCTION}

Architectures for Moon and Mars exploration are outlined in the Synthesis Grup Report America At The Threshold, America's space Exploration Initiative (Synthesis Group Report: 1991). This report discusses the key technologies for accomplishing the exploration of the Moon, Mars, and beyond. The Initiative visions include increasing our knowledge of the universe, advancing science and engineering, providing and maintain American preeminence in technological innovation and space leadership, stimulating technological innovations for the consumer marketplace, stimulating comuercialization of space, and strengthening ti.a U.S. economy. Technologies developed for the space Exploration Initiative (SEI) will have applications to other scientific fields, the commercial sector, and military applications. SEI technology, once developed, can be applied and reapplied to numerous programs, and give our industry a competitive advantage. These benefits will greatly strengthen our national economy, improve the quality of life, and support our technology leadership.

Technolr... transfer should be considered part of the design development process. It. is recommended that a technology transfer clause be considered part of design contracts and included in the evaluation and performance process. Incentive awards should be part of these contracts. This should apply to both government laboratories and industry.

Below is a discussion of some possible technology transfer ideas. These ideas are not meant to be complete because it is difficult to anticipate some of the most significant ones that could result, such as new design and manufacturing capabilities, higher quality products, better communication systems, improved transportation infrastructures, among others. These ideas were generated as a member of the synthesis Group and represents significant interactions with other members of the group.

\section{POWER}

Power systems for SEI can have significant commercial benefits. The development of high density, clean burning fuel cells can lead to practical electric vehicles. Also, fuel cells can be used in power utility load leveling 
and in conjunction with solar panels used as remote site power for such applications as cabins, remote pumps, water wells, and animal feeding facilities.

The challenge of building nuclear fission reactors for space could lead to a revitalization of the entire nuclear industry. New approaches to safety and longer lives with less maintenance could be introduced. Advanced reactor concepts, such as gas cores, could become economically viable. These would lead to almost 1008 fuel burnup, nuclear waste already separated from the fuel, on-line refueling, and greater safety. The reactors could be located terrestrially or in space. The environment would be subjected to much less pollution.

other benefits come from power beaming technology. For instance, semi-conducting lasers will have immediate benefits in making gallium arsenide integrated chips. These chips are 5 to 7 times faster than traditional gilicon chips.

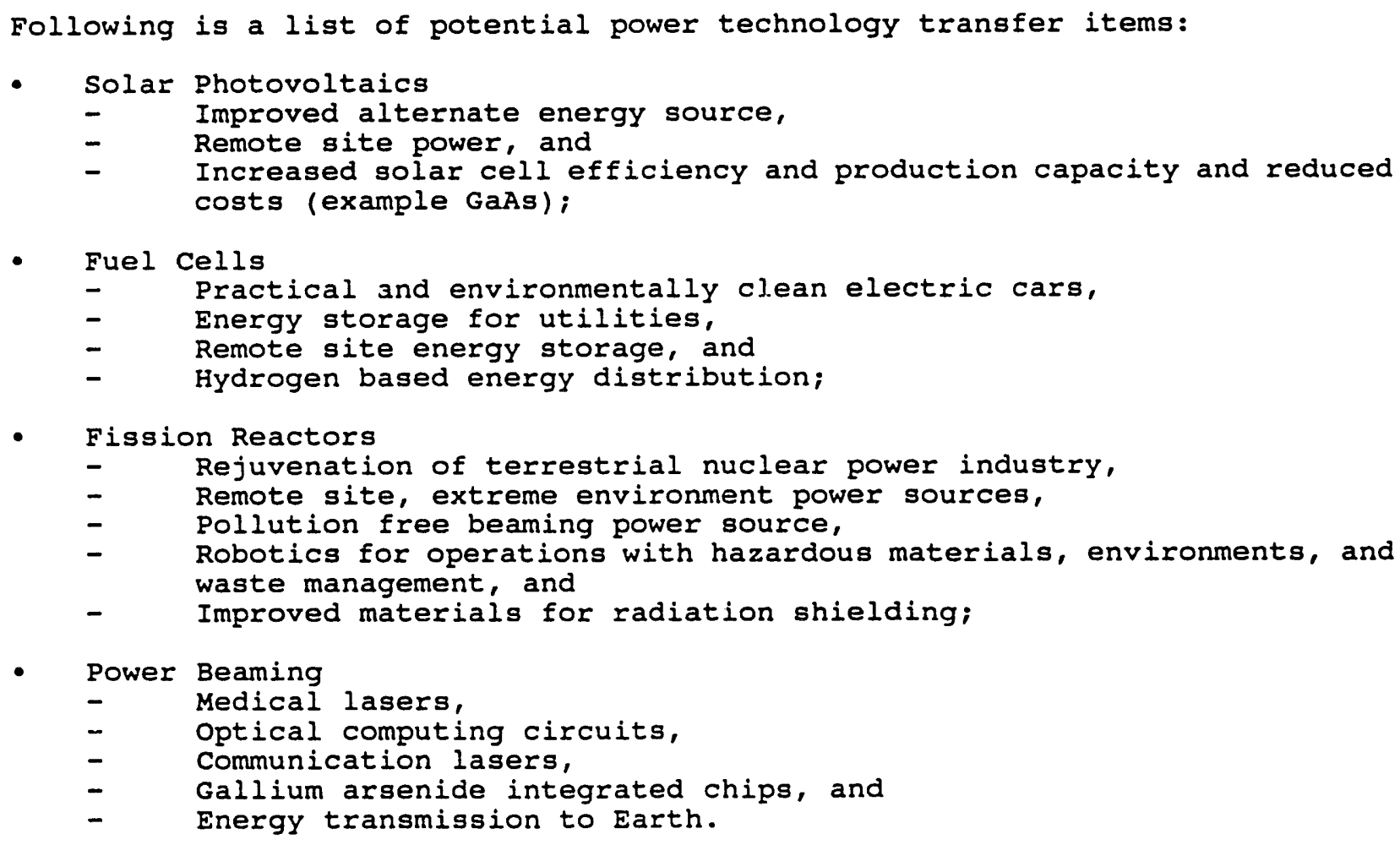

\section{PROPULSION}

Propulsion can be used to stimulate the use of hydrogen as a transportation fuel. Hydrogen has the advantage of being non-polluting when burned with oxygen. SEI will need to develop the technology to manufacture and store hydrogen for long periods of time. This makes an excellent fuel for high performance aircraft and research is on-going in this field at the present time.

Significant work will be done by SEI to improve materials. Iight weight tanks are a critical technology. This technology can be used to reduce the weight of vehicles while making the cars stronger for safety.

Possible technology transfer items are:

- Chemical

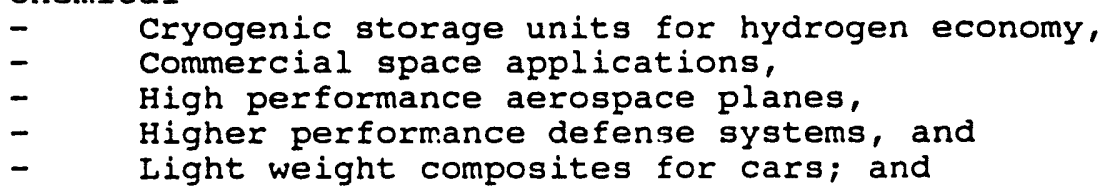


- Nuclear

- Gas core power reactors (terrestrial or space based),

- Higher temperature, more efficient power plants, and

- Space sommercialization.

\section{SPACECRAFT}

Highly automated spacecraft will be developed by SEI to operate on three year Mars missions. This will need to include built in fault detection systems that can also be used on aircraft, ships, power generation facilities, and other terrestrial facilities that need high reliable operations. The technologies to meet the premium on low weight can be used on aircraft, tanks, vehicles, buildings, and similar applications. The electronics will need to be very reliable with technology spin-offs to commercial and military aviation. The spacecraft must be armored against high speed meteorites; similar armor technology can be used to protect tanks and other objects against explosions.

possible technology transfer items are:

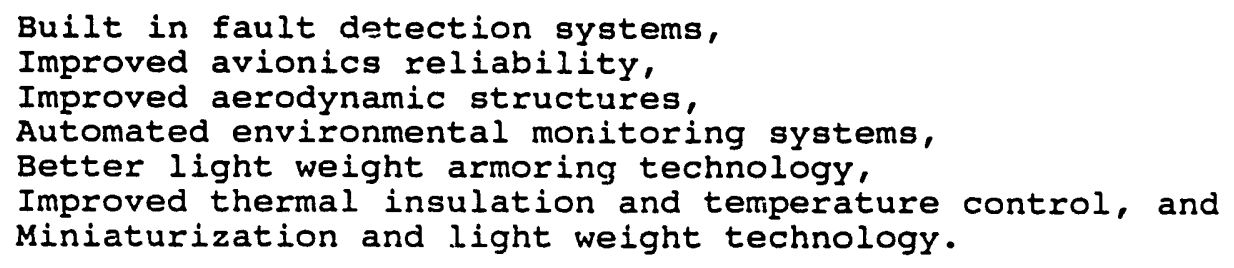

\section{ROBOTICS, ROVERS, MINING AND MANUFACTURING}

A new generation of robotic systems is anticipated as a result of SEI. SEI will depend on highly sophisticated robotics both in precursor missions and to support human missions. Similar systems can be used to handle all types of nuclear and chemical waste, for operating in hazardous environments such as around nuclear reactors or mines, for underwater exploration and construction, and in manufacturing processes. Telepresence, where the operator has a feel as to what is going on with the robot, offers much to society. Medical use of telerobots can include small units for internal surgery. Telepresence can offer students "hands-on" experience in mapping the surfaces of the Moon and Mars from their class rooms. It can be a major source of entertainment with the feel that you are actually participating in an activity from remote locations.

Rover technology can lead to a new class of off-highway vehicles. These would have the capability to avoid hazardous terrain and even operate in explosive environments like mines. The vehicles would be non-polluting with water the waste product.

Mining could be revolutionize with new energy efficient, low waste methods. These methods will be needed in space where energy is expensive and water is scarce. If the fusion helium-3 becomes the energy source of choice, the helium-3 will need to come from space.

The quality of the products needed for Mars is beyond the demands usually placed on terrestrial products. None or little maintenance during three years operations will be permitted. There will be no corner hardware stores for parts. This will lead to significant improvements in products built for use here on Earth. Very high quality goods will result. This will be reflected in new reliability technology, automated manufacturing systems, and improved materials. New products include high temperature heat pipes, improved fiber optics, and insulating thermally controlled windows.

Some possible technology transfer items are:

- Robotics

- Hazardous materials handling,

- Mapping and working in inaccessible areas,

- Hazardous environment operations, 


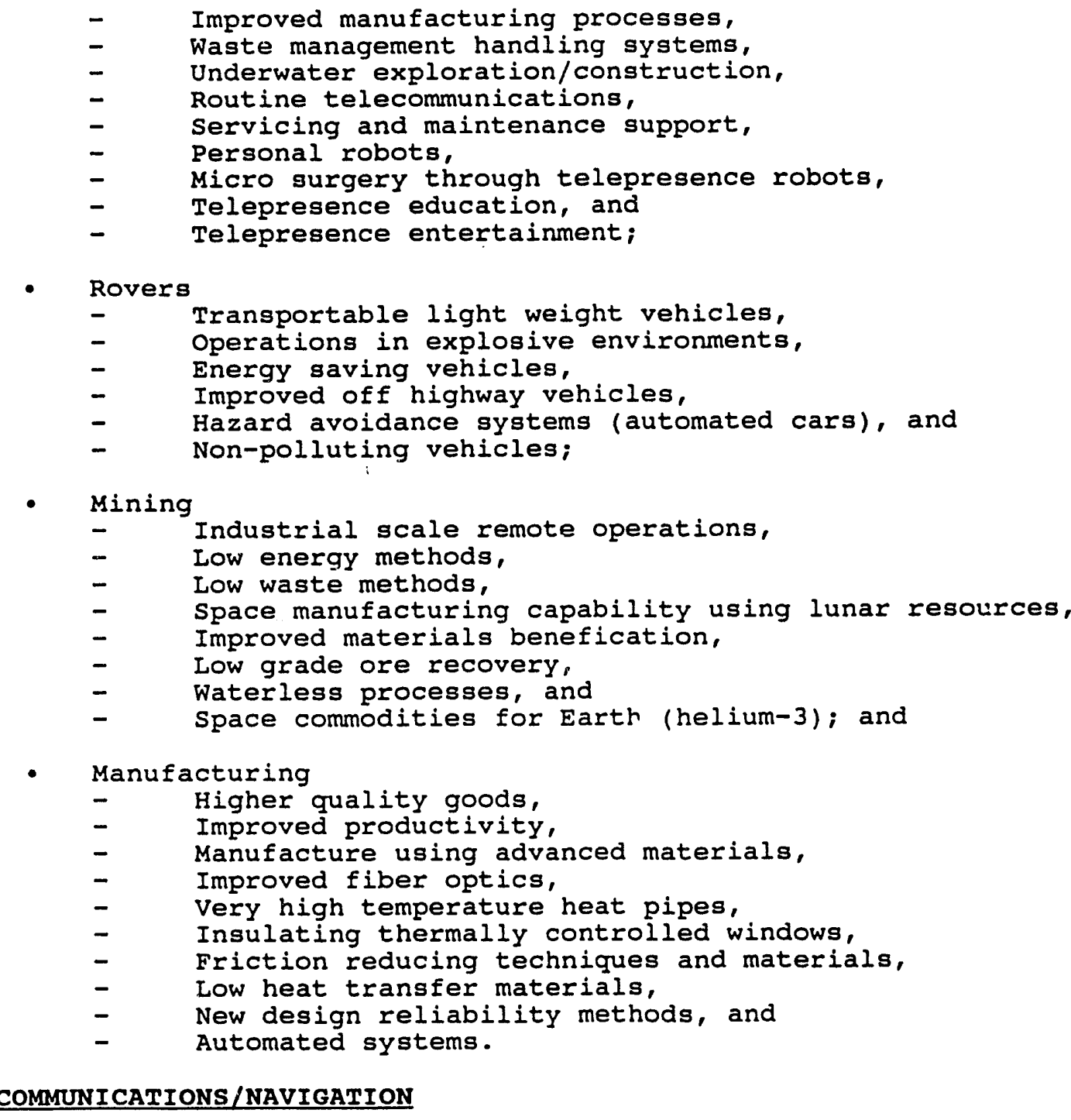

SEI will require orders of magnitude increases in data transmission. This will involve new data communication methods and data compression techniques to reduce the quantity of data to be transmitted. These methodologies can lead to wide spread information systems that can be accessed from anywhere in the country, world wide teleconferences as we enter the age of the single world economy, and practical systems for handling almost any telecommunication problem. One will be able to watch grandchildren grow up with our long distance family living arrangements.

Techniques for mapping other worlds will be applicable to making electronic maps that can be used for moving around this one. Having the ability to map weather on Mars will lead to better weather forecasting models here on Earth. The navigational aids for seI will need to be highly accurate and light weight--there are no gas stations on Mars for directions. The same technology can be applied to keep people from getting lost while hiking through the mountains. Also, it can be used as part of very precise air traffic control systems.

Potential technology transfer areas are:

- Video

- Very high data rate communications,

- Practical/cost effective televideo systems,

- Earth-Moon-Mars communications network, 
World wide teleconferencing, and

- Wide spread information systems; and

- Navigation/weather forecasting

- Highly accurate, world wide network,

- Light, portable user units,

- Tmproved electronic and paper maps,

- Better world wide weather models, and

- World wide air traffic control.

\section{HABITATS}

Light weight, self-gufficient, very reliable habitats will be developed by SEI. This type of facility has terrestrial application for transportable buildings for remote sites. Also, unique construction methods have potential applications that could be used in permanent buildings.

Potential technology transfer items are:

- New building construction methods,

- Transportable buildings to remote sites,

- Inflatables, fireproof, and

- Low outgassing materials for commercial and residential uses.

\section{IIFE SUPPORT}

Life support has many spin-offs from remote medical services to new treatments for cancer. A full range of life support sensors including human body monitors, radiation sensors and environmental sensors will be developed. These can be used to better monitor patients in hospitals or home and test the environment or work place for hazardous pollutants. Closed environments such as stationary underwater habitats and mobile ones such as environmental suits for fire fighters will benefit from SEI developments. Treatments for radiation exposure, osteoporosis, cancer and cardiovascular conditions will benefit from studies of weightlessness and radiation conditions in space. Farming methods from closed systems using hydroponics can support areas on Earth where land is limited. The whole subject of remote treatment of astronauts will lead to remote medical services on Earth.

Technical transfer ideas include:

- Systems

- Atmospheric and pollution monitoring sensors,

- Sensors for chemical process control,

- Computer medical aids,

- Underwater habitats,

- Closed for hazardous environments,

- Hazardous environmental suits,

- Waste management technology (water treatment, reuse, thermal recovery, solid waste recycle, compaction and energy conservation), - Food preservation,

- New aircraft and submarine life support systems,

- Understanding and treatment of osteoporosis processes,

- Biomonitors, and

- Hydroponics;

- Radiation protection

- Real-time continuous monitoring systems,

- Treatment for radiation exposures,

- More knowledgeable radiation standards,

- Improved solar flare forecast, and

- Prevention of human radiation damage;

- Medical

- Cancer research and treatment,

- Computerized diagnostics improvements, 


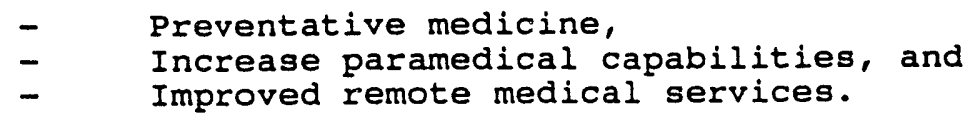

\section{INFRASTRUCTURE}

New design, testing, and qualification of products will be developed as part of SEI. Systems must last years with little or no maintenance. They must be designed with robotic servicing if necessary. This has direct application in product improvement and in maintaining U.S. capability in high technology areas. Some spin-offs can be the technology for an automated transportation system--cars can be placed on automatic control and the driver can relax. And, the infrastructure is in place for developing a space energy system to beam energy back to Earth. Also, students will be greatly stimulated by SEI. This stimulation will spill over to terrestrial systems.

Computers will be faster, smaller, longer life, more reliable, able to operate in more hazardous environments. Better techniques for developing software programs will allow many more applications of expert and artificial intelligent systems. These will allow routine servicing and maintenance on many products such as cars.

Potential technology transfer items are:

- Systems

- Design technology for higher reliable quality, less costly products,

- Systems engineering techniques for better products,

- Remote mapping/cartography and geodesy,

- Photography enhancement,

- Increase student interest,

- Commercial utility grid using power from space,

- Enhanced project management techniques, and

- Automated surface transport systems; and

- Computers

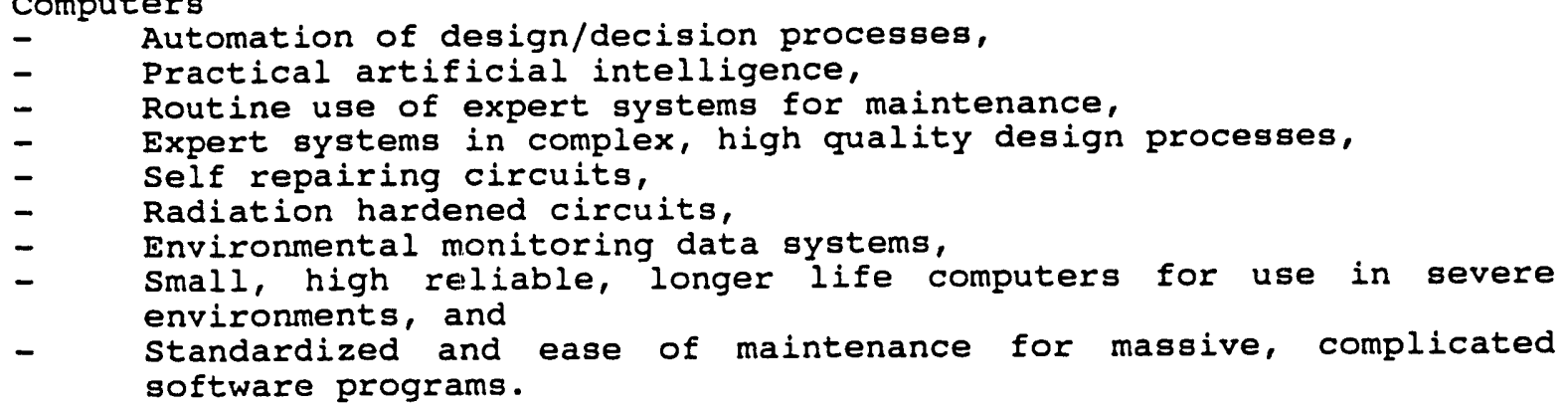

\section{CONCLUSIONS}

A significant number of potential technology trangfer items have been identified. These range from improved transportation to new forms of medical service. The Space Exploration Initiative truly has the potential to stimulate the U.S. economy and fulfill the visions of the synthesis Group.

\section{Acknowledgments}

This work was performed under the sponsorship of the U.S. Department of Energy, Idaho Field office, DOE contract \#DE-ACO7-76IDO1570.

\section{References}

Synthesis Group Report, America At The Threshold, America's Space Exploration Initiative, Superintendent of Documents, U.S. Government Printing Office, Washington, D.C. 20402 , June 1991. 

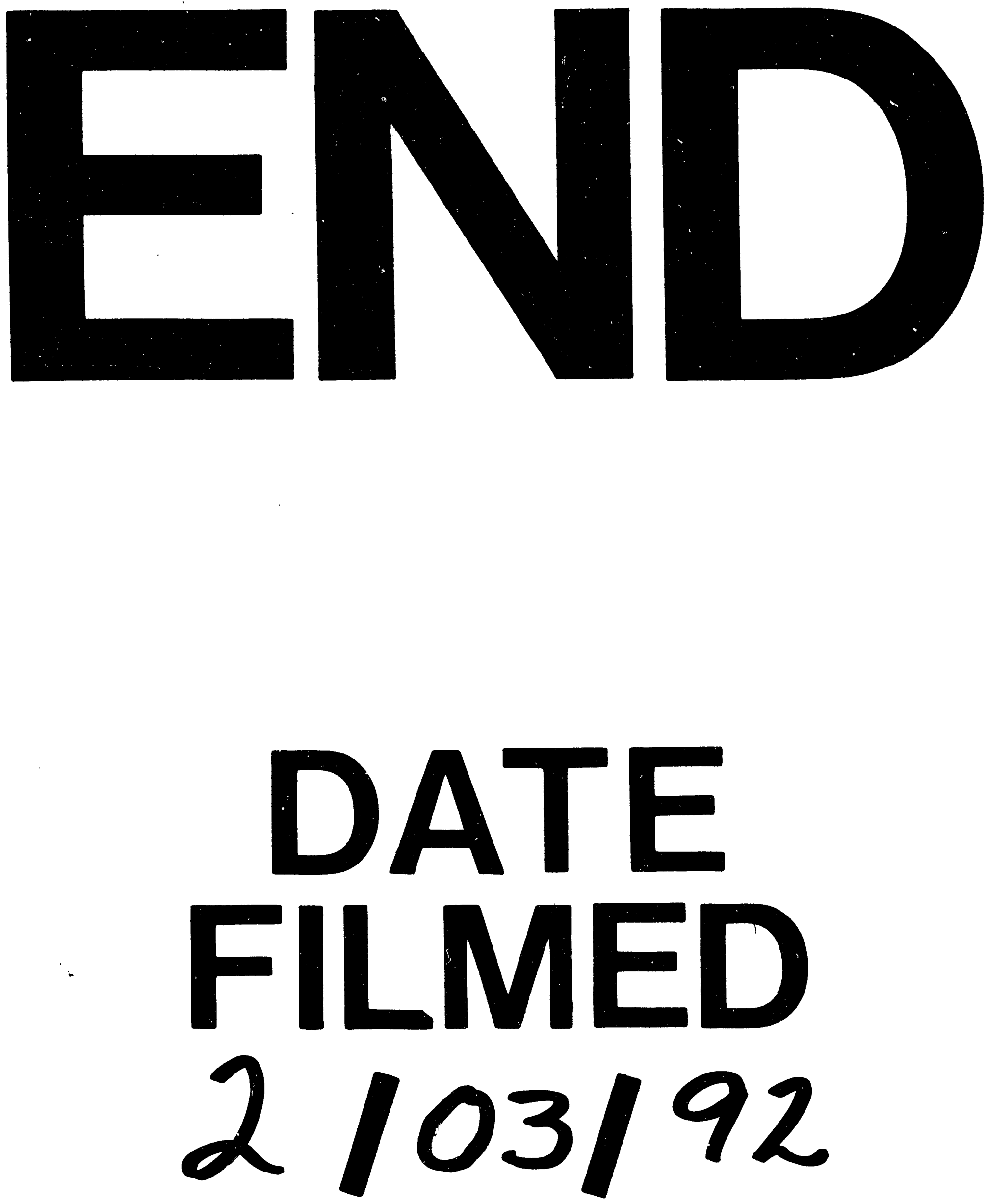
